\title{
Balloon Angioplasty of Native Coarctation and Comparison of Patients Younger and Older Than 3 Months
}

\author{
Cheng-Liang Lee, MD, PhD*,**; Jeng-Feng Lin, MD ${ }^{\dagger}$; Kai-Sheng Hsieh, MD*; \\ Chu-Chung Lin, MD*; Ta-Cheng Huang, MD*
}

\begin{abstract}
Background There is a high incidence of restenosis and aneurysm formation after balloon angioplasty for discrete native coarctation in neonates and young infants, and so the techniques remains controversial in this group of patients because its clinical validity, particularly in comparison with surgery, has not been well established. Methods and Results From January 1999 to October 2005, group A (17 patients [8 males, 9 females] $<3$ months old ranging from 0.2 to 2.9 months, with a body weight of $2.5-5.5 \mathrm{~kg}$ ) and group B (11 patients [5 males, 6 females] $>3$ months old ranging from 5.5 months to 6.4 years, with a body weight of $7.8-21 \mathrm{~kg}$ ) with discrete native coarctation who underwent balloon angioplasty and were included in this study. There were $13(76 \%)$ successes in group A, and 10 (90\%) successes in group B for the initial balloon angioplasty. There was no significant difference in success rate between groups A and B ( $>0.05)$. There were $9(69 \%)$ cases of restenosis patients in group A, and $2(20 \%)$ in group $\mathrm{B}$, a significant difference between the 2 groups $(\mathrm{p}<0.05)$. In group $\mathrm{A}, 1$ patient showed aneurysm formation after angioplasty, $1(5.8 \%)$ showed femoral artery obstruction and $2(11 \%)$ showed reduced pulses.

Conclusions Balloon angioplasty of discrete native coarctation is effective in patients both younger and older than 3 months. However, thea rates of restenosis, aneurysm formation, and approach artery injury are higher in patients younger than 3 months old when compared with patients aged over 3 months. These complications should be considered when performing balloon angioplasty in patients less than 3 months of age. (Circ J 2007; 71: $1781-1784$ )
\end{abstract}

Key Words: Aneurysm; Balloon angioplasty; Restenosis

B alloon angioplasty for native coarctation of the aorta was first described in $1982^{1}$ and since then, many studies have reported success for native and recurrent coarctation ${ }^{2-9}$ However, a high incidence of restenosis and aneurysm formation occurs in neonates and young infants ( $<3$ months $)^{10-13}$ a patent ductus arteriosus (PDA) in a neonate may result in restenosis, ${ }^{5-711}$ and so the clinical validity of balloon angioplasty, particularly in comparison with surgery, has not been well established, remaining controversial in this age group. In addition, balloon angioplasty has often failed in neonates with the combination of isthmic hypoplasia with long segment coarctation, ${ }^{14,15}$ so it is not recommended for such patients! ${ }^{11,12}$ Chinese and Western patients show an ethnic difference in congenital heart disease. Coarctation of the aorta is less common among Chinese patients $(1.2 \%$ of congenital heart disease) ${ }^{16,17}$ and we report here our experience of balloon angioplasty for patients younger and older than 3 months old.

(Received April 6, 2007; revised manuscript received July 18, 2007; accepted July 20, 2007)

*Department of Pediatrics, Kaohsiung Veterans General Hospital, **Institute of Biomedical Sciences, National Sun Yat-Sen University, Kaohsiung and Department of Pediatrics, Tian-Sheng Memorial Hospital, Pingtung, Taiwan

Mailing address: Ta-Cheng Huang, MD, Department of Pediatrics, Kaohsiung Veterans General Hospital, 386 Ta-Chung $1^{\text {st }}$ Road, Kaohsiung 813, Taiwan. E-mail: clleemd@yahoo.com.tw

\section{Methods}

Patients

From January 1999 to October 2005, there were 33 pediatric patients with discrete native coarctation who underwent balloon angioplasty at our institute and were included in this study. Group A comprised 17 patients (8 males, 9 females) younger than 3 months old (range 0.2-2.9 months; 5 patients $<1$ month old), with a body weight of $2.5-5.5 \mathrm{~kg}$ and group B comprised 11 patients ( 5 males, 6 females) older than 3 months old (range 5.5-6.4 years), with a body weight of $7.8-21 \mathrm{~kg}$. Informed consent for balloon dilation or surgery was given by patients or their parents. Five patients who had aortic isthmic hypoplasia with long segment coarctation and underwent further surgery were excluded. All the patients presented with heart murmur, and Doppler echocardiography revealed significant coarctation. By sphygmomanometry 26 patients, either without a PDA or with a small PDA, had a resting systolic blood pressure gradient greater than $20 \mathrm{mmHg}$ between the upper and lower limbs. The other 2 patients, who had a large right to left shunt PDA, did not have the $20-\mathrm{mmHg}$ blood pressure gradient and both had severe coarctation with a very small, stenotic diameter detected by 2-dimensional echocardiography. They required prostaglandin E1 infusion to maintain patency of the ductus arteriosus. Associated defects were present in 20 patients: ventricular septal defect (VSD) in 6; transposition of the great arteries (TGA) in 2; TGA plus VSD in 2; PDA in 2; VSD plus PDA in 5; atrial septal de- 
Table 1 Angiographic and Hemodynamic Data Before and After Balloon Angioplasty

\begin{tabular}{lccc}
\hline \hline & Group A $(n=17)$ & Group B $(n=11)$ & p value \\
\hline Age & $0.2-2.9(1.3 \pm 0.7)$ months & $0.5-6.4(2.8 \pm 2.1)$ years & \\
Body weight $(\mathrm{kg})$ & $2.50-5.5(3.9 \pm 0.7)$ & $7.8-21(13.4 \pm 4.2)$ & \\
Pre G $(\mathrm{mmHg})$ & $15-50(34 \pm 9)$ & $20-42(29 \pm 7)$ & \\
Post $G(\mathrm{mmHg})$ & $5-15(9.4 \pm 4.5)$ & $5-16(9.8 .2 \pm 3.4)$ & \\
Pre D $(\mathrm{mm})$ & $2.4-3.4(2.8 \pm 0.3)$ & $3.5-7.5(6.1 \pm 0.8)$ & \\
Post D $(\mathrm{mm})$ & $4.7-5.8(5.1 \pm 0.3)$ & $6.0-10.1(8.1 \pm 1.1)$ & \\
Initial success & $13(76 \%)$ & $10(90 \%)$ & 20.05 \\
Recurrence & $9(69 \%)$ & 0 & \\
Aneurysm & $1(5.8 \%)$ & $64-105(82.3 \pm 8.1)$ & \\
Procedure time (min) & $69-126(85.9 \pm 10.2)$ & $0.5-4.8(2.6 \pm 1.1)$ & \\
Follow-up (years) & $0.3-5.2(2.4 \pm 1.5)$ & & \\
\hline
\end{tabular}

Pre $G$ and post $G$, peak systolic gradient pre- and post-balloon angioplasty; Pre $D$ and Post $D$, diameter of coarctation pre-and post-balloon angioplasty.

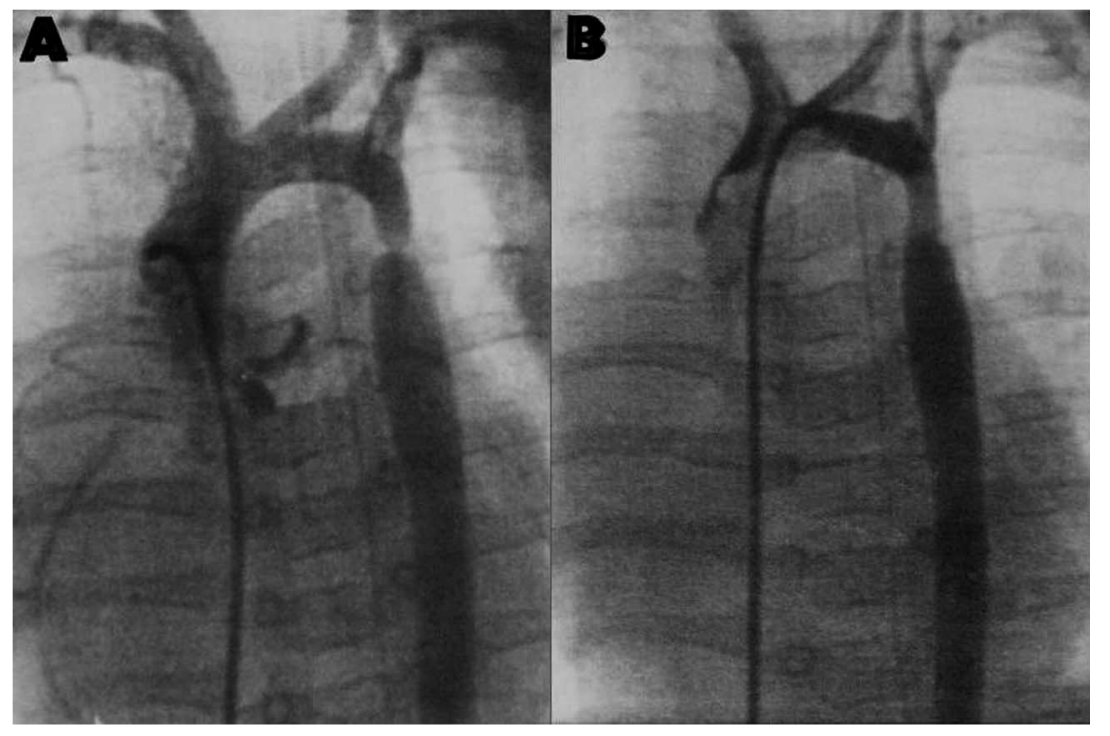

Fig 1. Coarctation before and after balloon angioplasty.

fect (ASD) plus PDA in 2; valvular aortic stenosis plus VSD plus PDA in 1 patient.

\section{Angioplasty Procedure}

The patients were given intravenous ketamine and midazolam anesthesia. The catheterization and angioplasty procedures were performed using a retrograde femoral arterial approach in all patients: in the 5 patients younger than 1 month old we used a 4Fr introducer sheath and a $5 \mathrm{Fr}$ sheath for the other 23 patients. The arterial catheter was placed from a retrograde approach, and the pressures of the ascending and descending aorta were obtained. Biplane angiography was performed before and after angioplasty in straight frontal and lateral projections. A 0.035 -inch, 260$\mathrm{cm}$ floppy-tip exchange guide wire was placed through an end hole catheter positioned above the aortic valve and this was maintained in the ascending aorta throughout the procedure. The balloon catheters were inserted over the wire. Patients were administered $50 \mathrm{IU} / \mathrm{kg}$ of heparin sulfate intravenously after vascular access was achieved. After conclusion of the procedure, intravenous heparin sulfate was given if the pedal arterial pulse was decreased or absent. If the pulse did not return $6 \mathrm{~h}$ after the procedure, urokinase was administered.

The initial diameter of the balloon for angioplasty was equal to or $1-2 \mathrm{~mm}$ greater than the diameter of the aorta at the level of the left subclavian artery and not greater than the diameter of the aorta at the diaphragm. The balloon was inflated under fluoroscopic guidance 2-3 times for each patient. The pressure of balloon inflation did not exceed that stated by the manufacturer. If a residual waist was evident at the coarctation site, the next largest balloon diameter was chosen for dilating the coarctation within the above guidelines.

\section{Catheterization Data}

The peak to peak systolic pressure gradient across the coarctation site was measured before and after angioplasty procedures. The diameters of the coarctation site were recorded. Most measurements were obtained from the systolic frames and lateral projections.

\section{Statistical Analysis}

The data are expressed as mean \pm standard deviation. The pre- and postdilation mean values of the peak to peak systolic ascending to descending aorta pressure gradient and diameter of coarctation were tested with paired t-test. Analysis of success and recurrence rate between groups A and B was undertaken using Fisher's exact test.

\section{Follow-up}

Patients were followed up at 1 day, 1 and 3 weeks, and 
then every 2 months for 1 year after angioplasty and at each half year thereafter. The follow-up included sphygmomanometric blood pressure measurements of the upper and lower limbs and Doppler ultrasound studies. If the patient had a pressure gradient of more than $20 \mathrm{mmHg}$ by sphygmomanometry or by Doppler ultrasound, then repeat angioplasty was considered.

\section{Results}

\section{Angioplasty Results}

The balloon angioplasty results are shown in the Table 1 . The mean value of the peak to peak systolic ascending to descending aorta pressure gradient significantly decreased from $34 \mathrm{mmHg}$ to $9.4 \mathrm{mmHg}$ in group $\mathrm{A}(\mathrm{p}<0.05)$, and from $29 \mathrm{mmHg}$ to $8.2 \mathrm{mmHg}$ in group $\mathrm{B}(\mathrm{p}<0.05)$ after balloon dilation. The mean diameter of coarctation significantly increased from $2.8 \mathrm{~mm}$ to $5.1 \mathrm{~mm}$ in group $\mathrm{A}$, and from $6.1 \mathrm{~mm}$ to $8.1 \mathrm{~mm}$ in group $\mathrm{B}(\mathrm{p}<0.05)$ after balloon dilation (Fig 1).

\section{Success Rate}

Balloon dilation was considered successful if the peak systolic pressure gradient across the coarctation site was less than $20 \mathrm{mmHg}$ and the coarcted segment increased in diameter by more than 50\%!1 There were 13 (76\%) successes in group A, and $10(90 \%)$ in group B for the initial balloon angioplasty. There was no significant difference between groups A and B in the success rate $(\mathrm{p}>0.05)$. Surgical relief of coarctation was required in 5 patients (4 in group A, 1 in group B) after balloon angioplasty.

\section{Follow-up and Recurrence Rate}

The follow-up time ranged from 2.5 months to 5.2 years (mean $\pm \mathrm{SD}=2.5 \pm 1.3$ year). There were $9(69 \%)$ cases of restenosis in group A, and $2(20 \%)$ in group B. There was a significant difference between groups $\mathrm{A}$ and $\mathrm{B}$ in the recurrence rate $(\mathrm{p}<0.05)$. In group A, 2 patients developed early restenosis 6 weeks after balloon dilation and 7 developed restenosis between 8 and 16 weeks. In group B, 1 patient developed restenosis at 12 weeks, and another at 14 weeks. More patients in group A had early restenosis than in group B. Among the 9 cases of restenosis in group A, 7 (77\%) patients underwent repeat balloon angioplasty, and all showed successful relief of coarctation, and $2(22 \%)$ required surgical relief and did not develop restenosis after operation. The 2 patients in group B both underwent repeat balloon angioplasty, which successfully relieved the coarctation. All the patients who underwent repeat balloon angioplasty were free from restenosis in the follow-up period. One of the 5 patients with failed initial balloon angioplasty underwent surgical treatment and developed restenosis 12 weeks after operation. Balloon dilation was performed successfully in this case.

Overall, 11 of 17 patients (64\%) in group A, and 10 of 11 patients $(90 \%)$ in group B had successful balloon angioplasty. There was no significant difference between groups $A$ and $B$ in the success rate $(p>0.05)$

\section{Complications}

One 6-day-old patient in group A showed aneurysm formation (Fig 2) after angioplasty. Her body weight was $3 \mathrm{~kg}$. She underwent $5-\mathrm{mm}$ balloon dilation and her systolic pressure gradient across the coarctation decreased from $40 \mathrm{mmHg}$ to $15 \mathrm{mmHg}$; the coarctation diameter increased

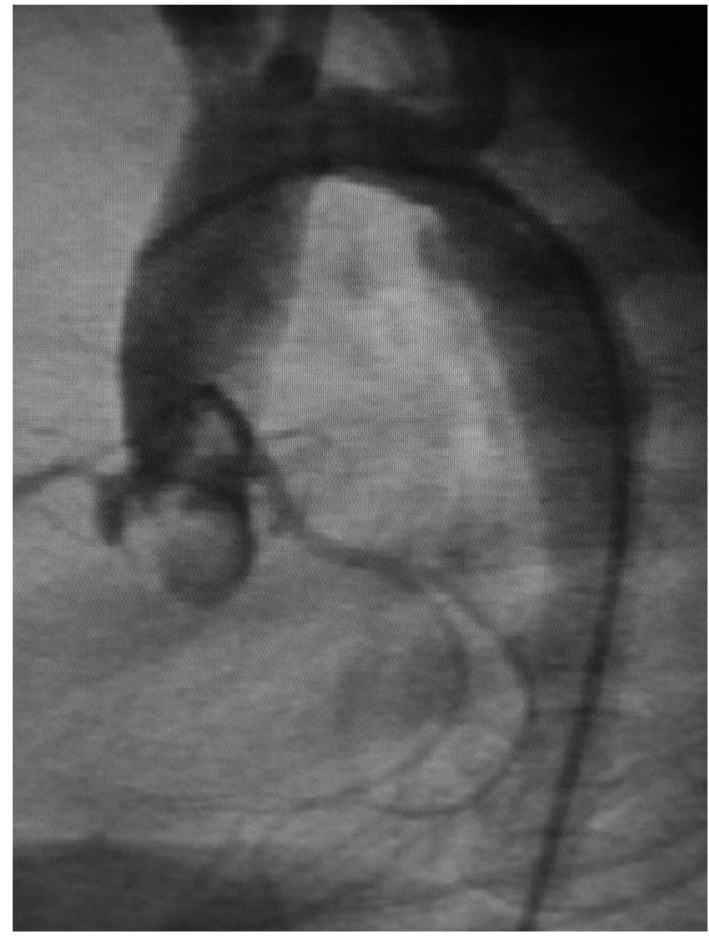

Fig 2. Aneurysm formation after balloon angioplasty.

from $2.5 \mathrm{~mm}$ to $4.6 \mathrm{~mm}$. There was no difference in the anatomy or technique used between this patient and those without aneurysm. There were no deaths related to the procedure. One patient in group A (5.8\%), who was 9-days-old with a body weight of $3 \mathrm{~kg}$, developed femoral artery obstruction, but this was resolved after heparin and urokinase infusion. Two patients in group A (11\%) developed reduced pulses: 1 was 9-days-old with a body weight of $3 \mathrm{~kg}$, and the other was 1-month-old with a body weight of $4 \mathrm{~kg}$, and both cases resolved after heparin infusion. No patient had a hemoglobin loss of more than $20 \%$ requiring pack red blood cell transfusion. No patient had significantly high blood pressure after procedure.

\section{Discussion}

Balloon angioplasty of native coarctation appears to be gaining more acceptance in children; ${ }^{18}$ however, in neonates and young infants, because of the high incidence of restenosis and aneurysm formation, the clinical validity, particular in comparison with surgery, has not been well established, so the technique remains controversial in these patients.

\section{Initial Success}

In other series the early success rate in infants aged 3 months or younger has ranged from $88 \%$ to $100 \% ?^{2-7,11,12}$ In our study, the initial success rate in group A was $76 \%$, which is similar to Western data. There was no difference in anatomy or technique associated with the failure of dilation. Comparing groups $\mathrm{A}$ and $\mathrm{B}$, the initial success rate was $76 \%$ and $90 \%$, respectively, so balloon angioplasty had a good initial result in both groups.

\section{Restenosis Rate}

The restenosis rate in infants aged 3 months and younger reportedly ranges from $50 \%$ to $71 \% ?^{2-7,11}$ In most cases 
(71-80\%), Except for a few patients needing operation, the restenosis could be treated by balloon angioplasty and the success rate was $80-100 \% 8,9$ In our study, 9 (69\%) of 13 followed-up patients in group A developed restenosis, which shows there is no difference between Western and Asian data. Seven (77\%) patients underwent repeat balloon angioplasty which was successful in all cases. Comparing groups $\mathrm{A}$ and $\mathrm{B}$, the restenosis rate was higher in group $\mathrm{A}$ (69\% and 20\%, respectively) and this difference was significant $(\mathrm{p}<0.05)$.

\section{Aneurysm Formation}

Both immediate- and late aneurysm formation have been reported and the incidence of aneurysm at the dilation site ranges from $0 \%$ to $5 \% 3,4,11,19$ However, there is not a consistent definition of aneurysm 3,4 We defined aneurysm as an out-pouching of the aorta, not present before angioplasty, which increased the nominal diameter of aorta by up to $20 \%$ ? In the present study, 1 patient in group A (5.8\%) had immediate aneurysm formation, which shows no difference between Western and Asian data. The aneurysm was apparent, but small in size, and seemed not to be dangerous, and was considered an acceptable. The small aneurysm was still present in the follow-up period. No patient in group B had aneurysm formation.

\section{Outcome of Associated Cardiac Defects}

All 8 cases of large posterior malalignment VSD underwent operation. Two of them had undergone pulmonary artery banding to correct heart failure prior to correction of the VSD. Of the 5 cases of membranous VSD ( $3-5 \mathrm{~mm}), 3$ closed spontaneously, and 3 were left unoperated as was the 1 cases of apical muscular VSD ( $3 \mathrm{~mm})$. The 4 TGA patients with or without VSD underwent operation, with 3 good results and 1 death from cardiac complication after operation. Of the 10 PDA patients, 2 underwent operation with no residual PDA, and 8 had coil embolization with no residual PDA. The 2 cases of small ASD ( $3 \mathrm{~mm}$ and $4 \mathrm{~mm})$ were left unoperated.

\section{Conclusion}

Balloon angioplasty of discrete native coarctation in both patients younger and older than 3 months of age is effective. However, restenosis, aneurysm formation, and approach artery injury are higher in patients younger than 3 months of age when compared with older patients. These complications should be considered when performing balloon angioplasty in patients younger than 3 months.

\section{Acknowledgment}

This study was supported by Kaohsiung Veterans General Hospital (grant no. VGHKS94-78).

\section{References}

1. Singer MI, Rowen M, Dorsey TJ. Transluminal aortic balloon angioplasty for coarctation of the aorta in the newborn. Am Heart J 1982; 103: $131-132$.

2. Rao PS, Jureidini SB, Balfour IC, Singh GK, Chen SC. Severe aortic coarctation in infants less than 3 months: Successful palliation by balloon angioplasty. J Invasive Cardiol 2003; 15: 202-208.

3. Fletcher SE, Nihill MR, Grifka RG, O'Laughlin MP, Mullins CE. Balloon angioplasty of native coarctation of the aorta: Mid-term follow-up and prognostic factors. J Am Coll Cardiol 1995; 25: 730734.

4. Mendelson AM, Lloyd TR, Crowley DC, Sandhu SK, Kocis KC, Beekman RH. Late follow-up of balloon angioplasty in children with a native coarctation of the aorta. Am J Cardiol 1994; 74: 696-700.

5. Rao PS, Galal O, Smith PA, Wilson AD. Five- to nine-year followup results of balloon angioplasty of native coarctation in infants and children. J Am Coll Cardiol 1996; 27: 462-470.

6. Yetman AT, Nykanen D, McCrindle BW, Sunnegardh J, Adatia I, Freedom RM, et al. Balloon angioplasty of recurrent coarctation: A 12-year review. J Am Coll Cardiol 1997; 30: 811-816.

7. Hellenbrand WE, Allen HD, Golinko RJ, Hagler DJ, Lutin W, Kan J. Balloon angioplasty for aortic coarctation: Results of valvuloplasty and angioplasty of congenital anomalies registry. Am J Cardiol 1990; 65: $793-797$.

8. Cowley CG, Orsmond GS, Feola P, McQuillan L, Shaddy RE. Longterm, randomized comparison of balloon angioplasty and surgery for native coarctation of aorta in childhood. Circulation 2005; 2111: $3453-3456$.

9. Suarez de Lezo J, Pan M, Romero M, Segura J, Pavlovic D, Ojeda S, et al. Percutaneous interventions on severe coarctation of the aorta: A 21-year experience. Pediatr Cardiol 2005; 26: 176-189.

10. Fiore AC, Fischer LK, Schwartz T, Jureidini S, Balfour I, Carpenter $\mathrm{D}$, et al. Comparison of angioplasty and surgery for neonatal aortic coarctation. Ann Thorac Surg 2005; 80: 1659-1664.

11. Park Y, Lucas VW, Sklansky MS, Kashani IA, Rothman A. Balloon angioplasty of native aortic coarctation in infants 3 months of age and younger. Am Heart J 1997; 134: 917-923.

12. Rao PS, Chopra PS, Koscik R, Smith PA, Wilson AD. Surgical versus balloon therapy for aortic coarctation in infants $<3$ months old. $J$ Am Coll Cardiol 1994; 23: 1479-1483.

13. Rao PS, Thapar MK, Kutayli F, Carey P. Causes of recoarctation after balloon angioplasty of unoperated aortic coarctation. J Am Coll Cardiol 1989; 13: 109-115.

14. Patel HT, Madani A, Paris YM, Warner KG, Hijazi ZM. Balloon angioplasty of native coarctation of the aorta in infants and neonates: Is it worth the hassle? Pediatr Cardiol 2001; 22: 53-57.

15. Kaine SF, Smith EO, Mott AR, Mullins CE, Geva T. Quantitative echocardiographic analysis of the aortic arch predicts outcome of balloon angioplasty of native coarctation of the aorta. Circulation 1996; 94: 1056-1062.

16. Lien WP, Chen JJ, Chen JH, Lin JL, Hsieh YY, Wu TL, et al. Frequency of various congenital heart diseases in Chinese adults: Analysis of 926 consecutive patients over 13 years of age. Am J Cardiol 1986; 57: 840-844.

17. Hsieh KS, Hwang BT, Meng LC. High incidence of right sided conotruncal abnormalities among the Chinese people: An unusual ethical difference. Circulation 1986; 74(Suppl II): 205.

18. McCrindle BW, Jones TK, Morrow WR, Hagler DJ, Lloyd TR, Nouri S, et al. Acute results of balloon angioplasty of native coarctation versus recurrent aortic obstruction are equivalent. J Am Coll Cardiol 1996; 28: 1810-1817.

19. Ovaert C, McCrindle BW, Nykanen D, MacDonald C, Freedom RM, Benson LN. Balloon angioplasty of native coarctation: Clinical outcomes and predictors of success. J Am Coll Cardiol 2000; 35: $988-$ 996. 